Bentham OPEN
CrossMark
Content list available at: www.benthamopen.com/TOOPHTJ/
DOI: $10.2174 / 1874364101610010044$

\title{
Detecting IOP Fluctuations in Glaucoma Patients
}

\author{
Brenda Nuyen ${ }^{1}$ and Kaweh Mansouri ${ }^{*}, 2,3$ \\ ${ }^{I}$ Hamilton Glaucoma Center and Department of Ophthalmology, University of California, San Diego, La Jolla, \\ California, USA \\ ${ }^{2}$ Glaucoma Center, Montchoisi Clinic, Genolier Swiss Vision Network, Lausanne, Switzerland \\ ${ }^{3}$ Department of Ophthalmology, University of Colorado School of Medicine, Aurora, Colorado, USA
}

\begin{abstract}
Lowering intraocular pressure (IOP) remains the guiding principle of glaucoma management. Although IOP is the only treatable risk factor, its 24-hour behavior is poorly understood. Current glaucoma management usually relies on single IOP measurements during clinic hours, even though IOP is a dynamic parameter with rhythms dependent on individual patients. It has further been shown that most glaucoma patients have their highest IOP measurements outside clinic hours. The fact that these IOP peaks go largely undetected may explain why certain patients progress in their disease despite treatment. Nevertheless, single IOP measurements have determined all major clinical guidelines regarding glaucoma treatment. Other potentially informative parameters, such as fluctuations in IOP and peak IOP, have been neglected, and effects of IOP-lowering interventions on such measures are largely unknown. Continuous 24-hour IOP monitoring has been an interest for more than 50 years, but only recent technological advances have provided clinicians with a device for such an endeavor. This review discusses current uses and shortcomings of current measurement techniques, and provides an overview on current and future methods for 24-hour IOP assessment. It may be possible to incorporate continuous IOP monitoring into clinical practice, potentially to reduce glaucoma-related vision loss.
\end{abstract}

Keywords: 24-h IOP monitoring, fluctuations, intraocular pressure, laucoma.

\section{INTRODUCTION}

Glaucoma is the most important cause of irreversible blindness worldwide [1]. Intraocular pressure (IOP) is not only one of the most significant risk factors in development of the disease, but also the only modifiable one. Accuracy of IOP measurement therefore is critical to predicting and monitoring the course of the disease.

IOP is the tension exerted by the aqueous humor as a result between its production and outflow from the globe. It is estimated as a transcorneal pressure gradient via indirect non-invasive tonometry, as there is at present time no safe and practical way to obtain the direct measurement. However, we will use the term "measurement" regarding IOP, as this has been used widely in the literature and in practice [2].

Many tonometry devices have been developed, each with applications in different clinical settings. Recent advances have aimed to address the biomechanical properties of the cornea, such as central corneal thickness (CCT) and corneal curvature, as they may confound accuracy. The most commonly used tonometers and their advantages and limitations are described here in detail. Goldmann applanation tonometry (GAT) currently is the gold standard, to which all other tonometers are compared. We also focus on new 24-hour IOP monitoring devices and methods, developed recently to record daily fluctuations especially during the nocturnal period.

\section{APPLANATION TONOMETRY}

Applanation tonometry is based on the Imbert-Fick law: [2] the force on the corneal outer surface reflects the

\footnotetext{
* Address correspondence to this author at the Glaucoma Center, Montchoisi Clinic, Genolier Swiss Vision Network, Chemin des Allinges 16, Chemin des Allinges 16, CH-1006 Lausanne, Switzerland; Tel: +41 2161937 42; Fax: +41 2161936 28, +41 216193742,41216193628 ; E-mail: kawehm@yahoo.com
} 
pressure at the inner cornea, which translates as the pressure in the anterior chamber. The estimated IOP would approach the "true" IOP if the structural properties of the cornea were virtually insignificant and the applanated area were infinitely small relative to the corneal surface area. However, not only are these two assumptions untrue in reality, but also the cornea itself, with the corneal surface tear film, presents an opposing force on the applanator. Applanation tonometry is most precise at the average CCT of $525 \mu \mathrm{m}$, and more studies are currently underway to determine the particular influence of the other corneal structural properties.

\section{GOLDMANN APPLANATION TONOMETER}

Developed in the 1950s [3], GAT involves a slit-lamp mounted device with a prism on the tip of the tonometer. This tip is placed against the central cornea, which has been anesthetized and stained with topical fluorescein dye. The tonometer head is gently advanced to apply force to the cornea, until the inner edges of the two half-circle mires make contact as viewed with a cobalt blue filter through the slit-lamp [4].

Although GAT is the most widely used tonometer worldwide, it has its limitations. GAT IOP readings are influenced by corneal structural parameters, the most studied of which is CCT. Lower CCT (less than $525 \mu \mathrm{m}$ ) is associated with IOP underestimation, and higher CCT (greater than $525 \mu \mathrm{m}$ ) with IOP overestimation [5, 6]. Furthermore, some studies have found that corneal thinness could be an independent risk factor for the progression of disease [7].

Corneal irregularities also influence the accuracy of GAT measurements. With significant astigmatism (greater than 3 diopters), the area applanated is elliptical rather than circular. Diseases that affect the corneal shape and structure also interfere with GAT accuracy. The more conical corneal shape found in keratoconus, a disease of corneal degeneration, impedes the accuracy and precision of GAT IOP measurement $[8,9]$. GAT tends to obtain much lower measurements at the conical apex, relative to the flatter and thicker regions of the cornea, and thus the overall GAT measurement in keratoconus tends to underestimate the IOP. Lastly, GAT IOP in eyes post corneal surgery is less accurate compared to non-surgerized eyes [10].

In summary, GAT is the most commonly used method of tonometry, but structural factors of the cornea limit its accuracy in practice. Formulas have been developed as an attempt to characterize and quantify these corneal properties, but no consensus exists regarding their use in the clinical setting [11]. Despite its limits, GAT remains the reference standard to which other, newer tonometers are compared.

\section{Perkins Handheld Tonometer}

The Perkins tonometer is a portable version of GAT, which does not require slit-lamp mounting. Therefore it is useful for patients unable to tolerate an upright slit-lamp examination, such as children, anesthesized or intubated patients, and patients who must be supine. Because the Perkins tonometer and GAT use the same principles of applanation tonometry, they share similar advantages and limitations. Their accuracy is similar, with a mean difference of $1.0 \mathrm{mmHg}[12,13]$. The Perkins tonometer also offers reasonable reliability, as shown in a study comparing several tonometers to GAT [14]. Thus the Perkins tonometer is a good choice for portable tonometry, given its similarity to GAT in method and accuracy.

\section{Non-Contact Tonometer}

The non-contact tonometer (NCT), otherwise known as the pneumatic applanation tonometer (not to be confused with the pneumatonometer), is essentially a Goldmann tonometer that uses an air puff as the applanating force. A burst of pressurized air transiently applanates the cornea, while the surface reflects light from a laser beam. The amount of light reflected during the time of applanation is compared to the time during which the surface is applanated by the air, and the IOP measurement is determined electronically. Other measurements are obtained in this process, including the ocular pulse amplitude and several values that assess the efficiency of aqueous outflow through the trabecular meshwork [4].

The NCT offers notable advantages, such as increased level of automation and lack of direct contact (and thus no risk of infection transmission) [15 - 17]. Cook et al., in a study comparing several tonometers, found that the NCT had the most precision in IOP measurement; more than $60 \%$ of its readings were within $2 \mathrm{mmHg}$ of that obtained by GAT [14]. However other studies have found that the NCT systematically overestimates by $0.12-0.58 \mathrm{mmHg}$, compared to GAT $[15,16,18]$. In addition, CCT may influence the NCT to a greater extent than it does GAT [19]. Patients also may 
squeeze their eyelids while awaiting the air puff, thereby interfering with accurate measurement using the NCT. Therefore, the NCT may be an easy-to-use IOP screening method, but measurements should be considered in light of the above limitations, especially corneal structural properties.

\section{OCULAR RESPONSE ANALYZER}

A modern version of non-contact tonometry is the ocular response analyzer (ORA). Its most noteworthy advantage is that it characterizes the biomechanical factors of the cornea that influence IOP measurement and can adjust readings in context of these properties. Using an air burst to applanate the cornea and an electro-optical system to measure readings, the ORA records two IOP values at the times the cornea is flattened: first, during inward applanation (as the cornea moves inward by the force of the air puff), and secondly, during outward applanation (as the cornea moves outward to return to its baseline). The cornea provides structural resistance during both processes, so the two IOP values are not the same. The difference between the values is corneal hysteresis $(\mathrm{CH})$ [20, 21]. $\mathrm{CH}$ may offer glaucoma risk information [4], as increased corneal elasticity has been associated with progression of disease [22, 23].

The ORA obtains three other measurements, in addition to $\mathrm{CH}$ : the corneal-compensated IOP (IOP $\left.{ }_{\mathrm{cc}}\right)$, $\mathrm{Goldmann}$ correlated IOP, and the corneal resistance factor (CRF) [24]. The $\mathrm{IOP}_{\mathrm{cc}}$ is less influenced by corneal biomechanical properties (most notably CCT [21]), when compared to GAT IOP readings [20, 25 - 28]. Additionally, the ORA does not require direct contact and thus avoids need for anesthesia and for tip disinfection. When compared to other tonometers in the setting of glaucoma, keratoconus, and post corneal surgery, the ORA performs rather well. In eyes with glaucoma, Sullivan-Mee et al. determined the ORA had reasonable repeatability and reproducibility when compared to GAT and the DCT (discussed below). Another study found disagreement in the IOP readings from the different tonometers, and that the most consistent factors correlating with measurement dissimilarity were ORAmeasured factors: $\mathrm{CH}$ and $\mathrm{CRF}$ [29]. Therefore in the setting of glaucoma, the ORA provides additional information to interpret accuracy in IOP measurement.

Even with improved accuracy and additionally clinically useful information, the ORA presents disadvantages as well. It lacks portability, as it requires mounting on a table, and requires frequent upkeep due to its complex electrooptical system [4]. But all in all, the ORA provides reliable and reproducible IOP measurements and clinically useful data, in various ophthalmologic settings [30,31]. Future studies involving the instrument can aid in elucidating further the role of the corneal structural properties in IOP measurement.

\section{CORVIS ST}

Another relatively new variation of the NCT, the Corvis ST (CST) uses a high speed camera to record the dynamic deformation of the cornea [32]. This method also allows detailed investigation of how corneal biomechanical factors change with the deformation caused by applanation, including corneal velocity, corneal applanation length, and corneal deformation amplitude [33]. Good agreement has been found between GAT and CST measurements [34]. However, controversy still exists regarding the effect of CCT on CST compared to its effect on other tonometers.

\section{INDENTATION TONOMETRY}

With indentation tonometry, a force will indent into a soft object more so than into a hard object [4]. Thus with the eye, the higher the IOP, the more weight or force that is necessary to push against and indent the cornea.

\section{SCHIOTZ TONOMETER}

Developed in 1905, the Schiotz tonometer uses a weighted plunger: for every $0.5 \mathrm{~mm}$ that the plunger indents into the cornea, the needle shows an increase of 1 unit. This scale reading is then converted into IOP in $\mathrm{mmHg}$. Its limitations include the requirement of the supine position for use, and a corneal abrasion theoretically is possible with the patient's eye movement. Frequent or prolonged measurement also can induce aqueous humor leak from the eye, so that subsequent measurements may be falsely low. The Schiotz tonometer is also affected by scleral rigidity, elasticity, and other structural properties of the eye; for example, increased (versus decreased) elasticity overestimates (versus underestimates) IOP.

\section{MACKAY-MARG TONOMETER}

Using both indentation and applanation principles, the MacKay-Marg tonometer is generally regarded as the most accurate and precise tonometer, even when compared to GAT [4]. The MacKay-Marg tonometer correlates well with 
other tonometers that use applanation [35].

Versus GAT, it may be less affected by corneal properties [36] and more accurate with scarred corneas [37]. The Tono-Pen uses the same principles, as a portable version of the MacKay-Marg tonometer.

\section{TONO-PEN XL}

The Tono-Pen XL is a direct successor to the MacKay-Marg tonometer and uses the same principles of indentation tonometry. It is portable, can be used in both supine and upright positions [38], and offers easy calibration and operation by using a digital readout. Besides basing the final IOP reading on a minimum of four measurements to increase precision, the Tono-Pen XL provides a value called the coefficient of variation: it must be less than 5\% for the IOP measurement to be considered accurate. The instrument also uses disposable latex covers and thus does not require tip sterilization. The Tono-Pen XL can measure IOP through bandage contact lenses, which makes it useful in settings such as chemical burns and neurotrophic keratopathy [39, 40]. It is more accurate than GAT in measuring IOP of eyes with irregular corneas, as its tip has a smaller contact area $\left(2.36 \mathrm{~mm}^{2}\right.$ for Tono-Pen XL versus $7.35 \mathrm{~mm}^{2}$ for GAT) [40].

Although directly related to the MacKay-Marg tonometer, the Tono-Pen XL has not been determined to be as accurate or precise as its predecessor. Close correlation has been found with GAT [41 - 43], but other studies show that the measurements of the Tono-Pen XL are far too different to be considered appropriate for clinical use [44, 45]. In one study, the Tono-Pen XL correlated well with GAT for IOP less than $20 \mathrm{mmHg}$, but for readings greater than $20 \mathrm{mmHg}$, the Tono-Pen XL demonstrated significant underestimation [46]. Salvetat et al. found the opposite result: higher IOP readings (greater than $24 \mathrm{mmHg}$ ) correlated with overestimation [47]. The accuracy and precision of the Tono-Pen XL therefore needs further clarification and study. The device is useful as a portable instrument and in the setting of irregular corneas as it has a relatively small contact area, but its IOP readings should be interpreted within the context of other factors such as IOP range and corneal properties (for example, CCT).

\section{PNEUMATONOMETER}

The pneumatonometer (PT; not to be confused with the pneumatic applanation tonometer) similarly uses both indentation and applanation techniques [48]. The cornea is indented gently by a flat tip on a pneumatic sensor floating on a column of area, and IOP is measured when the pressure applied equals the pressure exerted by the anterior chamber. The reading is available on a digital readout or as a paper tracing to provide real-time data, over the course of five to ten seconds. No inherent force is transmitted to the eye, compared to other tonometry techniques.

Because actual corneal contact is negligible with the instrument, the PT can reliably measure IOP with abnormal corneas: in contact lens wearers [49], in patients with corneal scarring and edema, and in patients with negligibly visible corneas. Similarly, it can easily be used with neurotrophic corneas. In eyes post LASIK, the PT was found to be more accurate than GAT [50]. The PT does not require a specific probe orientation [38] or a slit-lamp mount [4].

Some studies, however, have determined that the PT underestimates IOP at lower ranges (less than $10 \mathrm{mmHg}$ ) and overestimates IOP at higher ranges (greater than $25 \mathrm{mmHg}$ ) [51]. The PT has also been found to have significant correlation with CCT [52, 53]. The PT also has practical limitations, namely cost; the probe tips, air canisters, and graph paper require frequent replacement. All in all, however, the PT offers a practical and relatively accurate screening method, especially in eyes with abnormal corneal structure and shape.

\section{OTHER TYPES OF TONOMETERS}

\section{Rebound Tonometer}

Described by Dekking and Coster in 1967 [54], the iCare rebound tonometer (RT) is a portable device that uses a magnetized probe to make gentle contact transiently with the cornea. Speed of probe deceleration is correlated directly with higher IOP. The main advantage of the RT is ease of use, given its portability, use of disposable tips, and lack of anesthesia requirement. To enhance accuracy, it requires six measurements and determines mean pressure and standard deviation, after disregarding the highest and lowest readings [55]. Also, RT readings at the corneal periphery correlate well with those done at the central cornea, so that probe orientation has relatively little bearing on measurement accuracy [56, 57]. Therefore the RT is notably useful for eyes with post-surgical or abnormally shaped corneas [58, 59].

However, controversy still exists regarding the accuracy of the device. It has been shown that the RT overestimates IOP when compared to GAT [60 - 62], with differences ranging from $0.6 \mathrm{mmHg}$ [61] up to $7.7 \mathrm{mmHg}$ in eyes with 
higher IOP values [63]. Corneal properties, including CCT, CH, and CRF (but notably not corneal curvature) [56, 64], have been determined to affect RT IOP readings. A study did however determine that the intersession repeatability of the RT was similar to that of other tonometers, including the NCT and the Tono-Pen XL [65]. Other limitations of the RT include its inability of use in supine patients and its cost given the one-time use nature of the pins.

Overall, the RT is an easily used IOP screening device, which can be used among non-specialized personnel. It is mainly limited by its inability to account for corneal properties on IOP measurement [55].

\section{Dynamic Contour Tonometer}

The dynamic contour tonometer (DCT), i.e. the Pascal tonometer, was devised to be essentially free of corneal structural influence [66]. Instead of applanation or indentation, it operates via contour matching: the tip holds a cover shaped in the contour of the cornea, so that it avoids changing the shape of the cornea during the process. Theoretically the accuracy issues presented by corneal structural parameters are circumvented [67, 68]. The tip houses a pressure sensor that records IOP 100 times per second; from these readings, the device determines the mean IOP and the ocular pulse amplitude (OPA). The OPA is the difference between the average systolic and diastolic IOP, and thus a reflection of choroidal vessel filling. Therefore it can be used to represent ocular blood flow [55]. Low ORA has also been correlated with worsening glaucomatous progression [69].

Namely because of lessened influence of corneal biomechanical parameters, the DCT has been found to be more accurate compared to GAT [55]. Francis et al. determined that DCT readings are less influenced by CCT but still affected by the curvature of the cornea. However, the effect of this curvature on DCT still remained less than that of CCT on GAT [70]. With glaucomatous eyes, the DCT has improved repeatability and reproducibility compared to GAT and the ORA [71]. A study was done to compare GAT, the ORA, and the DCT on patients with primary open-angle glaucoma, ocular hypertension, normal-tension glaucoma, and glaucoma suspect [29]. There was a substantial dissimilarity in mean IOP measured by the three tonometers; the most consistent confounders of this discrepancy were determined by multi-regression analyses to be $\mathrm{CH}$ and CRF - values determined by the ORA. This is reasonable because the ORA records its measurements over more time and thus would be more influenced by corneal structure. Even though Milla et al. confirmed that corneal parameters had less impact on DCT readings, the group did determine that the DCT agreed well with GAT at CCT between 540 and $545 \mu \mathrm{m}$, but not at the extremes of corneal thickness [72].

The DCT has practical limitations as well. It lacks portability given it requires a slit-lamp mount, and it accrues cost associated with the disposable tips. It also requires prolonged tip contact, as well as specialized training for use. Despite limited evaluation thus far, the DCT promises to offer accurate and clinically useful evaluation of IOP measurement.

\section{Continuous IOP Monitoring}

The tonometers described above mainly measure IOP in single "snapshot" measurements, or over a span of at most several seconds. However it has been shown that IOP possesses a circadian rhythm with diurnal variation [73]. IOP can fluctuate as much as 4-5 mmHg in non-glaucomatous eyes, and even to a greater extent in eyes with glaucoma [74, 75]. As many as two-thirds of patients with glaucoma may have their highest IOP readings beyond regular clinic hours, especially during the night [76]. These large pressure shifts in fact play a role in dramatically worsening visual loss in patients with glaucoma [77, 78]. Therefore, continuous IOP monitoring would be a commendable goal especially to note IOP measurements at nighttime, when the highest IOP values occur [79].

Attempts to measure IOP frequently throughout the day have been made using two different strategies: (1) permanent and (2) temporary IOP monitoring. Several studies have offered promising results regarding permanent monitoring with non-human models, for example rabbit and non-human primate eyes [80, 81]. The major limitation of the methods using permanent IOP monitoring is the requirement for surgical implantation (in some cases, into bone) and the associated risks with such procedures. Surgical implantation may be circumvented with use of IOP sensors with intraocular lenses inserted during cataract extraction surgery. However, the use of these materials also has risks, including leakage of potentially toxic materials and need for regular invasive re-calibration. Also, only patients who participate in intraocular surgery could use such a method.

Temporary IOP monitoring may offer ways to avoid these risks and limitations of permanent monitoring. As early as the $1950 \mathrm{~s}$, researchers have been experimenting to find clinically useful, comfortable, and accurate portable ways to measure IOP continuously without permanent device implantation; these early models have ranged from metal indentating devices to magnetic pressure sensors to scleral buckle applanators [82, 83]. The ideal, clinically relevant $24-$ 
hour IOP measuring device must easily implantable via a minimally invasive procedure, and must provide stable uninterrupted contact with the eye [84]. Chitnis et al. developed in 2011 an implantable transponder that measures the "true" IOP in the vitreous body via a hydraulic system [84]. More recently, the main method of temporary IOP monitoring has involved contact lens tonometry, which involves a soft contact lens that can determine small fluctuations in ocular circumference that parallel changes in IOP. In human enucleated eyes, Hjortdal et al. determined that a change in IOP of $1 \mathrm{mmHg}$ was correlated with a change in corneal curvature of $3 \mu \mathrm{m}$, with a corneal radius of approximately $8 \mathrm{~mm}$ [85]. Another study corroborated the association between IOP and corneal curvature in vivo, by using positional change to induce change in IOP that corresponded well to change in ocular circumference measured at the limbus [86].

A gas-permeable, rigid contact lens was developed by Sanchez et al. in 2011 to measure IOP continuously for at least several hours [87]. Tested in enucleated porcine and in vivo human eyes, the contact lens is shaped similar to a doughnut, connecting to an on-person unit via sensor and recorder wires. IOP measurement correlated excellently with the lens sensor resistance response, even with blinking and eye movements. However, use of the device currently is restricted by poor transparency of the lens and limited tolerability by the patient.

Within the last several years, Leonardi et al. has tested a soft contact lens sensor (CLS) with embedded microfabricated strain gauges that measure changes in the dimensions of the globe, in response to changes in IOP [82]. This device was tested in enucleated porcine eyes, given that these eyes approached approximately the diameter of human eyes. The initial CLS used a wire connection between the contact lens and a recording instrument, and was able to approach rather well the "true" IOP (as measured by manometry inside the sample eyes) [88]. The wireless commercial device was subsequently developed by Sensimed and termed the Triggerfish CLS. The 14.1 mm diameter sensor on the lens measures changes in corneal curvature every five minutes for 30 seconds. The Triggerfish CLS possesses a microprocessor built to communicate with an external antenna, which is placed around the eye to transmit IOP measurement data to a recorder worn by the patient [83]. The recorder then transmits the data to a computer using Bluetooth technology. In a study of healthy volunteers over the course of several months, the Triggerfish CLS was found to measure IOP accurately and reproducibly, compared to the NCT and GAT [89]. It also confirms the presence of and aids to characterize the daily and nocturnal variations in IOP [90].

Prospective clinical investigations have studied the safety and side effect profile of the Triggerfish CLS in healthy and glaucomatous subjectspatients, with no significant safety issues found [91]. In a study of ten healthy students, De Smedt et al. determined that the Triggerfish CLS had high tolerability and scored well on comfort, despite transient effects such as mild corneal abrasions and decrease in visual acuity during/immediately after CLS wear in several subjects [92]. In a study of 15 glaucoma patients, Mansouri et al. similarly found good tolerability and safety, with complications typical of soft contact lens wear - here, one case of corneal erosion and several cases of dry eye syndrome and superficial punctate keratopathy [93]. The investigators also confirmed with the device that the peak IOP did in fact occur during the nocturnal period. In a follow up study, the group again found no significant adverse effects, only conjunctival hyperemia, which occurred in about half of the subjects [94].

In order to use the Triggerfish CLS, patients currently need a prescription and training by healthcare professionals for use. However in the future, patients ideally would be able to obtain and use a CLS device easily. Patients still would need to be educated about the safety of contact lens wear, and use may be limited in those with dry eye syndrome or other corneal pathologies.

Another recent CLS design, developed by Chen et al., lacks an embedded chip, instead using a capacitator and coil to sense corneal deformation [95]. Thus it is thinner than the Triggerfish CLS, which uses an embedded silicon chip. The thinner lens may potentially allow for improved contact with the corneal surface and more accurate measurements. Initial studies show promising linearity between IOP and sensing performance of the coil.

The CLS thus far proves to be a promising method for frequent, round-the-clock IOP measurements. Just as diabetic patients are encouraged to keep home logs to facilitate in-office evaluation and management, patients with glaucoma would greatly benefit from data available through 24-hour IOP monitoring.

\section{DISCUSSION}

Spanning from GAT to the newer methods, the various tonometry methods described above offer different advantages and limitations. Some tonometers demonstrate their ideal accuracy as in-office devices, to diagnose accurately and guide disease management, and others are best utilized as practical simple-to-use population screening 
tools.

In the ophthalmology clinic setting, GAT remains the reference standard, even over fifty years after its development. GAT has benefited from decades of evaluation: it has determined our current definitions of "normal" and "goal" IOP in glaucoma management, and it has been the most widely used device to assess degree of IOP lowering by current glaucoma medications and procedures. However, other tonometers such as the DCT and ORA offer additional clinically useful data not provided by GAT, such as ocular pulse amplitude (former) and parameters describing corneal structure (latter). They also bypass certain limitations observed with GAT, including the unaccounted-for influence of corneal biomechanical properties and the structural irregularities of pathologic or post-surgical corneas.

On the other hand, ease of use is more critical in the screening setting. All featuring portability, the Perkins tonometer, Tono-Pen XL, PT, and RT are relatively simple to learn how to use, and are able to evaluate IOP sufficiently in non-ideal situations - for example, in the supine position or in eyes from which bandage contact lenses cannot be removed. Perhaps in the future these instruments may be used routinely in the home as well so that patients can learn to record their IOP measurements on a regular basis.

In-home IOP measurement is a goal that recently has become realistically attainable. In the last several years, 24hour IOP monitoring devices have made substantial progress. Besides proving reasonable accuracy, comfort, and safety, they have also already contributed to understanding of IOP circadian variation, especially in the nocturnal phase. Development and evaluation of improved and commercially available continuous-wear devices are currently in the works. In the mean time, patients and their ophthalmologists have a variety of tonometry devices at their fingertips to aid in diagnosis and management of glaucoma.

\section{CONFLICT OF INTEREST}

The authors confirm that this article content has no conflict of interest.

\section{ACKNOWLEDGEMENTS}

Declared none.

\section{REFERENCES}

[1] Resnikoff S, Pascolini D, Etya'ale D, et al. Global data on visual impairment in the year 2002. Bull World Health Organ 2004; 82(11): 844-51. [PMID: 15640920]

[2] De Moraes CG, Prata TS, Liebmann J, Ritch R. Modalities of tonometry and their accuracy with respect to corneal thickness and irregularities. J Optom 2008; 1(2): 43-9.

[http://dx.doi.org/10.3921/joptom.2008.43]

[3] Goldmann H, Schmidt T. [Applanation tonometry]. Ophthalmologica 1957; 134(4): 221-42. [http://dx.doi.org/10.1159/000303213] [PMID: 13484216]

[4] Stamper RL. A history of intraocular pressure and its measurement. Optom Vis Sci 2011; 88(1): E16-28. [http://dx.doi.org/10.1097/OPX.0b013e318205a4e7] [PMID: 21150677]

[5] Whitacre MM, Stein RA, Hassanein K. The effect of corneal thickness on applanation tonometry. Am J Ophthalmol 1993; $115(5)$ : 592-6. [http://dx.doi.org/10.1016/S0002-9394(14)71455-2] [PMID: 8488910]

[6] Herndon LW, Choudhri SA, Cox T, Damji KF, Shields MB, Allingham RR. Central corneal thickness in normal, glaucomatous, and ocular hypertensive eyes. Arch Ophthalmol 1997; 115(9): 1137-41.

[http://dx.doi.org/10.1001/archopht.1997.01100160307007] [PMID: 9298054]

[7] Brandt JD, Beiser JA, Kass MA, Gordon MO. Central corneal thickness in the ocular hypertension treatment study (OHTS). Ophthalmology 2001; 108(10): 1779-88.

[http://dx.doi.org/10.1016/S0161-6420(01)00760-6] [PMID: 11581049]

[8] Böhm A, Kohlhaas M, Lerche RC, Bischoff B, Richard G. [Measuring intraocular pressure in keratoconus. Effect of the changed biomechanics]. Ophthalmologe 1997; 94(11): 771-4. [http://dx.doi.org/10.1007/s003470050201] [PMID: 9465707]

[9] Papastergiou GI, Kozobolis V, Siganos DS. Assessment of the pascal dynamic contour tonometer in measuring intraocular pressure in keratoconic eyes. J Glaucoma 2008; 17(6): 484-8.

[http://dx.doi.org/10.1097/IJG.0b013e3181622502] [PMID: 18794685]

[10] Ismail AR, Lamont M, Perera S, et al. Comparison of IOP measurement using GAT and DCT in patients with penetrating keratoplasties. Br J Ophthalmol 2007; 91(7): 980-1.

[http://dx.doi.org/10.1136/bjo.2006.099564] [PMID: 17576716] 
[11] Gunvant P, O’Leary DJ, Baskaran M, Broadway DC, Watkins RJ, Vijaya L. Evaluation of tonometric correction factors. J Glaucoma 2005; 14(5): 337-43. [http://dx.doi.org/10.1097/01.ijg.0000176940.81799.33] [PMID: 16148580]

[12] Wozniak K, Köller AU, Spörl E, Böhm AG, Pillunat LE. [Intraocular pressure measurement during the day and night for glaucoma patients and normal controls using Goldmann and Perkins applanation tonometry]. Ophthalmologe 2006; 103(12): $1027-31$. [http://dx.doi.org/10.1007/s00347-006-1407-7] [PMID: 17048019]

[13] Baskett JS, Goen TM, Terry JE. A comparison of Perkins and Goldmann applanation tonometry. J Am Optom Assoc 1986; $57(11)$ : 832-4. [PMID: 3782712]

[14] Cook JA, Botello AP, Elders A, et al. Systematic review of the agreement of tonometers with Goldmann applanation tonometry. Opthalmology 2012; 119(8): 1552-7.

[http://dx.doi.org/10.1016/j.ophtha.2012.02.030]

[15] Jorge J, Díaz-Rey JA, González-Méijome JM, Almeida JB, Parafita MA. Clinical performance of the Reichert AT550: a new non-contact tonometer. Ophthalmic Physiol Opt 2002; 22(6): 560-4. [http://dx.doi.org/10.1046/j.1475-1313.2002.00077.x] [PMID: 12477021]

[16] Parker VA, Herrtage J, Sarkies NJ. Clinical comparison of the Keeler Pulsair 3000 with Goldmann applanation tonometry. Br J Ophthalmol 2001; 85(11): 1303-4. [http://dx.doi.org/10.1136/bjo.85.11.1303] [PMID: 11673293]

[17] Moseley MJ, Evans NM, Fielder AR. Comparison of a new non-contact tonometer with Goldmann applanation. Eye (Lond) 1989; 3(Pt 3): $332-7$.

[http://dx.doi.org/10.1038/eye.1989.48] [PMID: 2612679]

[18] Gupta V, Sony P, Agarwal HC, Sihota R, Sharma A. Inter-instrument agreement and influence of central corneal thickness on measurements with Goldmann, pneumotonometer and noncontact tonometer in glaucomatous eyes. Indian J Ophthalmol 2006; 54(4): 261-5. [http://dx.doi.org/10.4103/0301-4738.27952] [PMID: 17090879]

[19] Domke N, Hager A, Wiegand W. [Intraocular pressure and corneal thickness. A comparison between non-contact tonometry and applanation tonometry]. Ophthalmologe 2006; 103(7): 583-7. [http://dx.doi.org/10.1007/s00347-006-1364-1] [PMID: 16786183]

[20] Broman AT, Congdon NG, Bandeen-Roche K, Quigley HA. Influence of corneal structure, corneal responsiveness, and other ocular parameters on tonometric measurement of intraocular pressure. J Glaucoma 2007; 16(7): 581-8 .

[21] Medeiros FA, Weinreb RN. Evaluation of the influence of corneal biomechanical properties on intraocular pressure measurements using the ocular response analyzer. J Glaucoma 2006; 15(5): 364-70. [http://dx.doi.org/10.1097/01.ijg.0000212268.42606.97] [PMID: 16988597]

[22] Wells AP, Garway-Heath DF, Poostchi A, Wong T, Chan KC, Sachdev N. Corneal hysteresis but not corneal thickness correlates with optic nerve surface compliance in glaucoma patients. Invest Ophthalmol Vis Sci 2008; 49(8): 3262-8. [http://dx.doi.org/10.1167/iovs.07-1556] [PMID: 18316697]

[23] Congdon NG, Broman AT, Bandeen-Roche K, Grover D, Quigley HA. Central corneal thickness and corneal hysteresis associated with glaucoma damage. Am J Ophthalmol 2006; 141(5): 868-75. [http://dx.doi.org/10.1016/j.ajo.2005.12.007] [PMID: 16527231]

[24] Sullivan-Mee M, Billingsley SC, Patel AD, Halverson KD, Alldredge BR, Qualls C. Ocular Response Analyzer in subjects with and without glaucoma. Optom Vis Sci 2008; 85(6): 463-70. [http://dx.doi.org/10.1097/OPX.0b013e3181784673] [PMID: 18521025]

[25] Laiquzzaman M, Bhojwani R, Cunliffe I, Shah S. Diurnal variation of ocular hysteresis in normal subjects: relevance in clinical context. Clin Experiment Ophthalmol 2006; 34(2): 114-8. [http://dx.doi.org/10.1111/j.1442-9071.2006.01185.x] [PMID: 16626423]

[26] Touboul D, Roberts C, Kérautret J, et al. Correlations between corneal hysteresis, intraocular pressure, and corneal central pachymetry. J Cataract Refract Surg 2008; 34(4): 616-22. [http://dx.doi.org/10.1016/j.jcrs.2007.11.051] [PMID: 18361984]

[27] Hager A, Schroeder B, Sadeghi M, Grossherr M, Wiegand W. [The influence of corneal hysteresis and corneal resistance factor on the measurement of intraocular pressure]. Ophthalmologe 2007; 104(6): 484-9. [http://dx.doi.org/10.1007/s00347-007-1532-y] [PMID: 17587093]

[28] Hager A, Loge K, Schroeder B, Füllhas M-O, Wiegand W. Effect of central corneal thickness and corneal hysteresis on tonometry as measured by dynamic contour tonometry, ocular response analyzer, and Goldmann tonometry in glaucomatous eyes. J Glaucoma 2008; 17(5): $361-5$.

[http://dx.doi.org/10.1097/IJG.0b013e31815c3ad3] [PMID: 18703945]

[29] Sullivan-Mee M, Lewis SE, Pensyl D, Gerhardt G, Halverson KD, Qualls C. Factors influencing intermethod agreement between goldmann applanation, pascal dynamic contour, and ocular response analyzer tonometry. J Glaucoma 2013; 22(6): 487-95. [http://dx.doi.org/10.1097/IJG.0b013e31824cd08d] [PMID: 22407388]

[30] Moreno-Montañés J, Maldonado MJ, García N, Mendiluce L, García-Gómez PJ, Seguí-Gómez M. Reproducibility and clinical relevance of 
the ocular response analyzer in nonoperated eyes: corneal biomechanical and tonometric implications. Invest Ophthalmol Vis Sci 2008; 49(3): 968-74.

[http://dx.doi.org/10.1167/iovs.07-0280] [PMID: 18326720]

[31] González-Méijome JM, Queirós A, Jorge J, Díaz-Rey A, Parafita MA. Intraoffice variability of corneal biomechanical parameters and intraocular pressure (IOP). Optom Vis Sci 2008; 85(6): 457-62.

[http://dx.doi.org/10.1097/OPX.0b013e3181783a5f] [PMID: 18521024]

[32] Hon Y, Lam AK. Corneal deformation measurement using Scheimpflug noncontact tonometry. Optom Vis Sci 2013; 90(1): e1-8. [http://dx.doi.org/10.1097/OPX.0b013e318279eb87] [PMID: 23238261]

[33] Ali NQ, Patel DV, McGhee CN. Biomechanical responses of healthy and keratoconic corneas measured using a noncontact scheimpflugbased tonometer. Invest Ophthalmol Vis Sci 2014; 55(6): 3651-9.

[http://dx.doi.org/10.1167/iovs.13-13715] [PMID: 24833745]

[34] Bañeros-Rojas P, Martinez-de-la-Casa JM, Arribas-Pardo P, Berrozpe-Villabona C, Toro-Utrera P, García-Feijoó J. [Comparison between Goldmann, Icare Pro and Corvis ST tonometry]. Arch Soc Esp Oftalmol 2014; 89(7): 260-4. [http://dx.doi.org/10.1016/j.oftal.2014.02.001] [PMID: 24814401]

[35] Augsburger A, Terry JE. Non-contact and Mackay-Marg tonometry: comparison in patients ages 7 to 85 years. Am J Optom Physiol Opt $1977 ;$ 54(1): 31-4. [http://dx.doi.org/10.1097/00006324-197701000-00004] [PMID: 871146]

[36] Stepanik J. Das mackay-marg-tonometer. Albr Von Graefes Arch Clin Exp Ophthalmol 1973; 188(3): 211-6.

[37] Kaufman HE, Wind CA, Waltman SR. Validity of Mackay-Marg electronic applanation tonometer in patients with scarred irregular corneas. Am J Ophthalmol 1970; 69(6): 1003-7. [http://dx.doi.org/10.1016/0002-9394(70)91047-0] [PMID: 5423765]

[38] Currie BD, Bagga H, Rademaker AW, Tanna AP. Effect of instrument orientation on the accuracy of intraocular pressure measurements in human cadaveric eyes: manometric evaluation of the model 30 classic Pneumatonometer and Tono-Pen XL. J Glaucoma 2011; 20(8): 465-9. [http://dx.doi.org/10.1097/IJG.0b013e3181f46324] [PMID: 20852435]

[39] Mark LK, Asbell PA, Torres MA, Failla SJ. Accuracy of intraocular pressure measurements with two different tonometers through bandage contact lenses. Cornea 1992; 11(4): 277-81. [http://dx.doi.org/10.1097/00003226-199207000-00001] [PMID: 1424645]

[40] Azuara-Blanco A, Bhojani TK, Sarhan AR, Pillai CT, Dua HS. Tono-Pen determination of intraocular pressure in patients with band keratopathy or glued cornea. Br J Ophthalmol 1998; 82(6): 634-6. [http://dx.doi.org/10.1136/bjo.82.6.634] [PMID: 9797663]

[41] Minckler DS, Baerveldt G, Heuer DK, Quillen-Thomas B, Walonker AF, Weiner J. Clinical evaluation of the Oculab Tono-Pen. Am J Ophthalmol 1987; 104(2): 168-73.

[http://dx.doi.org/10.1016/0002-9394(87)90010-9] [PMID: 3618714]

[42] Kao SF, Lichter PR, Bergstrom TJ, Rowe S, Musch DC. Clinical comparison of the Oculab Tono-Pen to the Goldmann applanation tonometer. Ophthalmology 1987; 94(12): 1541-4. [http://dx.doi.org/10.1016/S0161-6420(87)33249-X] [PMID: 3431824]

[43] Boothe WA, Lee DA, Panek WC, Pettit TH. The Tono-Pen. A manometric and clinical study. Arch Ophthalmol 1988; $106(9)$ : $1214-7$. [http://dx.doi.org/10.1001/archopht.1988.01060140374035] [PMID: 3415545]

[44] Kooner KS, Cooksey JC, Barron JB, Zimmerman TJ, Gupte RK, Wall JL. Tonometry comparison: Goldmann versus Tono-Pen. Ann Ophthalmol 1992; 24(1): 29-36.

[PMID: 1543324]

[45] Farrar SM, Miller KN, Shields MB, Stoup CM. An evaluation of the Tono-Pen for the measurement of diurnal intraocular pressure. Am J Ophthalmol 1989; 107(4): 411-6. [http://dx.doi.org/10.1016/0002-9394(89)90666-1] [PMID: 2929709]

[46] Horowitz GS, Byles J, Lee J, D’Este C. Comparison of the Tono-Pen and Goldmann tonometer for measuring intraocular pressure in patients with glaucoma. Clin Experiment Ophthalmol 2004; 32(6): 584-9. [http://dx.doi.org/10.1111/j.1442-9071.2004.00907.x] [PMID: 15575828]

[47] Salvetat ML, Zeppieri M, Tosoni C, Brusini P. Comparisons between Pascal dynamic contour tonometry, the TonoPen, and Goldmann applanation tonometry in patients with glaucoma. Acta Opthalmol Scand 2007; 85(3): 272-9. [http://dx.doi.org/10.1111/j.1600-0420.2006.00834.x]

[48] Moses RA, Grodzki WJ Jr. The pneumatonograph. A laboratory study. Arch Ophthalmol 1979; 97(3): 547-52. [http://dx.doi.org/10.1001/archopht.1979.01020010291023] [PMID: 420643]

[49] Scibilia GD, Ehlers WH, Donshik PC. The effects of therapeutic contact lenses on intraocular pressure measurement. CLAO J 1996; 22(4): 262-5. [PMID: 8906384]

[50] Bayraktar S, Bayraktar Z. Central corneal thickness and intraocular pressure relationship in eyes with and without previous LASIK: comparison of Goldmann applanation tonometer with pneumatonometer. Eur J Ophthalmol 2005; 15(1): 81-8. 


\section{[PMID: 15751244]}

[51] Tonnu P-A, Ho T, Newson T, et al. The influence of central corneal thickness and age on intraocular pressure measured by pneumotonometry, non-contact tonometry, the Tono-Pen XL, and Goldmann applanation tonometry. Br J Ophthalmol 2005; 89(7): 851-4. [http://dx.doi.org/10.1136/bjo.2004.056622] [PMID: 15965165]

[52] Saleh TA, Adams M, McDermott B, Claridge KG, Ewings P. Effects of central corneal thickness and corneal curvature on the intraocular pressure measurement by Goldmann applanation tonometer and ocular blood flow pneumatonometer. Clin Experiment Ophthalmol 2006; 34(6): 516-20. [http://dx.doi.org/10.1111/j.1442-9071.2006.01266.x] [PMID: 16925697]

[53] Morgan AJ, Harper J, Hosking SL, Gilmartin B. The effect of corneal thickness and corneal curvature on pneumatonometer measurements. Curr Eye Res 2002; 25(2): 107-12.

[http://dx.doi.org/10.1076/ceyr.25.2.107.10162] [PMID: 12525964]

[54] Dekking HM, Coster HD. Dynamic tonometry. Ophthalmologica 1967; 154(1): 59-74. [http://dx.doi.org/10.1159/000305149] [PMID: 6059593]

[55] ElMallah MK, Asrani SG. New ways to measure intraocular pressure. Curr Opin Ophthalmol 2008; 19(2): 122-6. [http://dx.doi.org/10.1097/ICU.0b013e3282f391ae] [PMID: 18301285]

[56] Chui WS, Lam A, Chen D, Chiu R. The influence of corneal properties on rebound tonometry. Ophthalmology 2008; $115(1): 80-4$. [http://dx.doi.org/10.1016/j.ophtha.2007.03.061] [PMID: 17573114]

[57] González-Méijome JM, Jorge J, Queirós A, et al. Age differences in central and peripheral intraocular pressure using a rebound tonometer. Br J Ophthalmol 2006; 90(12): 1495-500.

[http://dx.doi.org/10.1136/bjo.2006.103044] [PMID: 16885185]

[58] Moreno-Montañés J, García N, Fernández-Hortelano A, García-Layana A. Rebound tonometer compared with goldmann tonometer in normal and pathologic corneas. Cornea 2007; 26(4): 427-30. [http://dx.doi.org/10.1097/ICO.0b013e318030df6e] [PMID: 17457191]

[59] Cervino A. Rebound tonometry: new opportunities and limitations of non-invasive determination of intraocular pressure. Br J Ophthalmol 2006; 90(12): 1444-6. [http://dx.doi.org/10.1136/bjo.2006.102970] [PMID: 17114589]

[60] Vincent SJ, Vincent RA, Shields D, Lee GA. Comparison of intraocular pressure measurement between rebound, non-contact and Goldmann applanation tonometry in treated glaucoma patients. Clin Experiment Ophthalmol 2012; 40(4): e163-170. [http://dx.doi.org/10.1111/j.1442-9071.2011.02670.x]

[61] Van der Jagt LH, Jansonius NM. Three portable tonometers, the TGDc-01, the ICARE and the Tonopen XL, compared with each other and with Goldmann applanation tonometry. Ophthalmic Physiol Opt 2005; 25: 429-35.

[62] Nakamura M, Darhad U, Tatsumi Y, et al. Agreement of rebound tonometer in measuring intraocular pressure with three types of applanation tonometers. Am J Ophthalmol 2006; 142(2): 332-4. [http://dx.doi.org/10.1016/j.ajo.2006.02.035] [PMID: 16876523]

[63] Martinez-de-la-Casa JM, Garcia-Feijoo J, Castillo A, Garcia-Sanchez J. Reproducibility and clinical evaluation of rebound tonometry. Invest Ophthalmol Vis Sci 2005; 46(12): 4578-80. [http://dx.doi.org/10.1167/iovs.05-0586] [PMID: 16303951]

[64] Jóhannesson G, Hallberg P, Eklund A, Lindén C. ICare and Goldmann applanation tonometry-a comparative study. Acta Ophthalmol 2008; 86: 614-21.

[65] Davies LN, Bartlett H, Mallen EA, Wolffsohn JS. Clinical evaluation of rebound tonometer. Acta Ophthalmol Scand 2006; 84(2): 206-9. [http://dx.doi.org/10.1111/j.1600-0420.2005.00610.x] [PMID: 16637838]

[66] Kanngiesser HE, Kniestedt C, Robert YC. Dynamic contour tonometry: presentation of a new tonometer. J Glaucoma 2005; 14(5): 344-50. [http://dx.doi.org/10.1097/01.ijg.0000176936.16015.4e] [PMID: 16148581]

[67] Kniestedt C, Lin S, Choe J, Bostrom A, Nee M, Stamper RL. Clinical comparison of contour and applanation tonometry and their relationship to pachymetry. Arch Ophthalmol 2005; 123(11): 1532-7. [http://dx.doi.org/10.1001/archopht.123.11.1532] [PMID: 16286615]

[68] Kotecha A, White ET, Shewry JM, Garway-Heath DF. The relative effects of corneal thickness and age on Goldmann applanation tonometry and dynamic contour tonometry. Br J Ophthalmol 2005; 89(12): 1572-5. [http://dx.doi.org/10.1136/bjo.2005.075580] [PMID: 16299132]

[69] Weizer JS, Asrani S, Stinnett SS, Herndon LW. The clinical utility of dynamic contour tonometry and ocular pulse amplitude. J Glaucoma 2007; 16(8): 700-3.

[http://dx.doi.org/10.1097/IJG.0b013e31806ab2fe] [PMID: 18091458]

[70] Francis BA, Hsieh A, Lai M-Y, et al. Effects of corneal thickness, corneal curvature, and intraocular pressure level on Goldmann applanation tonometry and dynamic contour tonometry. Opthalmology 2007; 114(1): 20-6. [http://dx.doi.org/10.1016/j.ophtha.2006.06.047]

[71] Sullivan-Mee M, Gerhardt G, Halverson KD, Qualls C. Repeatability and reproducibility for intraocular pressure measurement by dynamic contour, ocular response analyzer, and goldmann applanation tonometry. J Glaucoma 2009; 18(9): 666-73. 
[http://dx.doi.org/10.1097/IJG.0b013e31819c487d] [PMID: 20010245]

[72] Milla E, Duch S, Buchacra O, Masuet C. Poor agreement between Goldmann and Pascal tonometry in eyes with extreme pachymetry. Eye (Lond) 2009; 23(3): 536-42.

[http://dx.doi.org/10.1038/eye.2008.90] [PMID: 18369376]

[73] Mansouri K, Weinreb RN, Medeiros FA. Is 24-hour intraocular pressure monitoring necessary in glaucoma? Semin Ophthalmol 2013; 28(3): $157-64$. [http://dx.doi.org/10.3109/08820538.2013.771201] [PMID: 23697618]

[74] Liu JH, Kripke DF, Twa MD, et al. Twenty-four-hour pattern of intraocular pressure in the aging population. Invest Ophthalmol Vis Sci 1999; 40(12): 2912-7. [PMID: 10549652]

[75] Liu JH, Zhang X, Kripke DF, Weinreb RN. Twenty-four-hour intraocular pressure pattern associated with early glaucomatous changes. Invest Ophthalmol Vis Sci 2003; 44(4): 1586-90.

[http://dx.doi.org/10.1167/iovs.02-0666] [PMID: 12657596]

[76] Barkana Y, Anis S, Liebmann J, Tello C, Ritch R. Clinical utility of intraocular pressure monitoring outside of normal office hours in patients with glaucoma. Arch Ophthalmol 2006; 124(6): 793-7. [http://dx.doi.org/10.1001/archopht.124.6.793] [PMID: 16769832]

[77] Caprioli J, Coleman AL. Intraocular pressure fluctuation a risk factor for visual field progression at low intraocular pressures in the advanced glaucoma intervention study. Ophthalmology 2008; 115(7): 1123-1129.e3. [http://dx.doi.org/10.1016/j.ophtha.2007.10.031] [PMID: 18082889]

[78] Quaranta L, Katsanos A, Russo A, Riva I. 24-hour intraocular pressure and ocular perfusion pressure in glaucoma. Surv Ophthalmol 2013; 58 (1): $26-41$

[79] Kóthy P, Vargha P, Holló G. Ocuton-S self tonometry vs. Goldmann tonometry; a diurnal comparison study. Acta Ophthalmol Scand 2001; 79(3): 294-7.

[http://dx.doi.org/10.1034/j.1600-0420.2001.790317.x] [PMID: 11401642]

[80] Todani A, Behlau I, Fava MA, et al. Intraocular pressure measurement by radio wave telemetry. Invest Ophthalmol Vis Sci 2011; 52(13): 9573-80.

[http://dx.doi.org/10.1167/iovs.11-7878] [PMID: 22039243]

[81] Downs JC, Burgoyne CF, Seigfreid WP, Reynaud JF, Strouthidis NG, Sallee V. 24-hour IOP telemetry in the nonhuman primate: implant system performance and initial characterization of IOP at multiple timescales. Invest Ophthalmol Vis Sci 2011; 52(10): 7365-75. [http://dx.doi.org/10.1167/iovs.11-7955] [PMID: 21791586]

[82] Leonardi M, Leuenberger P, Bertrand D, Bertsch A, Renaud P. First steps toward noninvasive intraocular pressure monitoring with a sensing contact lens. Invest Ophthalmol Vis Sci 2004; 45(9): 3113-7. [http://dx.doi.org/10.1167/iovs.04-0015] [PMID: 15326128]

[83] Yung E, Trubnik V, Katz LJ. An overview of home tonometry and telemetry for intraocular pressure monitoring in humans. Graefes Arch Clin Exp Ophthalmol 2014; 252(8): 1179-88. [http://dx.doi.org/10.1007/s00417-014-2668-5]

[84] Chitnis G, Maleki T, Samuels B, Cantor LB, Ziaie B. A minimally invasive implantable wireless pressure sensor for continuous IOP monitoring. IEEE Trans Biomed Eng 2013; 60(1): 250-6. [http://dx.doi.org/10.1109/TBME.2012.2205248] [PMID: 22736631]

[85] Hjortdal JO, Jensen PK. In vitro measurement of corneal strain, thickness, and curvature using digital image processing. Acta Ophthalmol Scand 1995; 73(1): 5-11.

[http://dx.doi.org/10.1111/j.1600-0420.1995.tb00004.x] [PMID: 7627759]

[86] Lam AKC, Douthwaite WA. The effect of an artificially elevated intraocular pressure on the central corneal curvature. Opthalmic Physiol Opt 1997; 17(1): 18-24.

[87] Sánchez I, Laukhin V, Moya A, et al. Prototype of a nanostructured sensing contact lens for noninvasive intraocular pressure monitoring. Invest Ophthalmol Vis Sci 2011; 52(11): 8310-5. [http://dx.doi.org/10.1167/iovs.10-7064] [PMID: 21948548]

[88] Leonardi M, Pitchon EM, Bertsch A, Renaud P, Mermoud A. Wireless contact lens sensor for intraocular pressure monitoring: assessment on enucleated pig eyes. Acta Ophthalmol 2009; 87(4): 433-7. [http://dx.doi.org/10.1111/j.1755-3768.2008.01404.x] [PMID: 19016660]

[89] Mottet B, Aptel F, Romanet J-P, Hubanova R, Pépin J-L, Chiquet C. 24-hour intraocular pressure rhythm in young healthy subjects evaluated with continuous monitoring using a contact lens sensor. JAMA Ophthalmol 2013; 131(12): 1507 -6.

[90] Agnifili L, Mastropasqua R, Frezzotti P, et al. Circadian intraocular pressure patterns in healthy subjects, primary open angle and normal tension glaucoma patients with a contact lens sensor. Acta Ophthalmol 2015; 93(1): e14-21. [http://dx.doi.org/10.1111/aos.12408] [PMID: 24720477]

[91] Lorenz K, Korb C, Herzog N, et al. Tolerability of 24-hour intraocular pressure monitoring of a pressure-sensitive contact lens. J Glaucoma 2013; 22(4): $311-6$ 
[92] De Smedt S, Mermoud A, Schnyder C. 24-hour intraocular pressure fluctuation monitoring using an ocular telemetry Sensor: tolerability and functionality in healthy subjects. J Glaucoma 2012; 21(8): 539-44. [http://dx.doi.org/10.1097/IJG.0b013e31821dac43] [PMID: 21602707]

[93] Mansouri K, Shaarawy T. Continuous intraocular pressure monitoring with a wireless ocular telemetry sensor: initial clinical experience in patients with open angle glaucoma. Br J Ophthalmol 2011; 95(5): 627-9. [http://dx.doi.org/10.1136/bjo.2010.192922] [PMID: 21216796]

[94] Mansouri K, Medeiros FA, Tafreshi A, Weinreb RN. Continuous 24-hour monitoring of intraocular pressure patterns with a contact lens sensor: safety, tolerability, and reproducibility in patients with glaucoma. Arch Ophthalmol 2012; 130(12): 1534-9. [http://dx.doi.org/10.1001/archophthalmol.2012.2280]

[95] Chen G-Z, Chan I-S, Leung LK, Lam DC. Soft wearable contact lens sensor for continuous intraocular pressure monitoring. Med Eng Phys 2014; 36(9): 1134-9. [http://dx.doi.org/10.1016/j.medengphy.2014.06.005] [PMID: 25034639]

Received: July 26, 2015 Revised: August 18, 2015 Accepted: August 18, 2015

(C) Nuyen and Mansouri; Licensee Bentham Open.

This is an open access article licensed under the terms of the Creative Commons Attribution-Non-Commercial 4.0 International Public License (CC BY-NC 4.0) (https://creativecommons.org/licenses/by-nc/4.0/legalcode), which permits unrestricted, non-commercial use, distribution and reproduction in any medium, provided the work is properly cited. 